\title{
Performance Assessment of Solar Cooling Systems with Energy Storage
}

\author{
Giovanni Brumana ${ }^{1 *}$, Giuseppe Franchini ${ }^{1}$ and Elisa Ghirardi $^{1}$ \\ ${ }^{1}$ University of Bergamo, Department of Engineering and Applied Sciences, Viale Marconi 5, Dalmine \\ 24044 (BG), Italy
}

\begin{abstract}
The paper presents a complete solar cooling comparison. A detailed model of a tertiary sector building has been evaluated in three locations (Riyadh, Abu Dhabi, and Palermo) and coupled with four solar cooling systems: two solar thermal cooling systems ( $\mathrm{Li}-\mathrm{Br}$ absorption chiller and adsorption chiller), a solar Desiccant Evaporative Cooling system and a solar electric cooling (Photovoltaic coupled with Compression chiller). A multi-variable optimization procedure selects the optimal size of each component. The results show that the solar cooling system based on absorption chiller satisfied the cooling demand regardless of the site location whilst the performance of the Desiccant Evaporative Cooling system is dramatically affected by ambient conditions. The electric solar cooling option shows the best overall efficiency and appears a costeffective solution despite the high cost of the storage system.
\end{abstract}

\section{Introduction}

The environmental issues and global warming are driving the continuous installation of new air conditioning systems, affecting the consequent increasing demand for electric energy driving the increase in consumption of energy available resources. Recently, the global energy request related to cooling systems has grown to account for $10 \%$ of world energy consumption and $14 \%$ of peak demand [1] and, for the Arabian Peninsula, 65\% of electric consumption is due to the air conditioning equipment [2]. To improve the efficiency and sustainability of cooling systems, the scientific community is studying new technologies and new air conditioning systems, based on the exploitation of renewable energies. Among the available solution, the adoption of solar cooling systems represents the most promising way in terms of primary energy consumption [3].

Solar cooling is a promising technology able to switch the solar radiation, main source of air conditioning demand, into the cooling production. Among the most innovative solution [4], the most common and commercial application includes close circuit as Absorption chiller and Adsorption chiller, and the open circuit as Desiccant Evaporative [5]. A different solution, based on the common vapor compression chiller coupled with photovoltaic modules is sometimes not considered a solar cooling system due to the indirect connection between energy source and chiller. Nevertheless, electric solar cooling represents a very convenient solution thanks to the easy integration with the existing energy infrastructure and considering the large diffusion of the

\footnotetext{
* Corresponding author: giovanni.brumana@unibg.it
} 
systems [6]. The crucial aspect of PV-driven solar cooling is the electric energy storage [7] also considering the high cost of Li-Ion battery [8] [9].

The scientific works assess the solar cooling systems in terms of improving efficiency and reliability. The introduction of energy storage plays an important role in the aim of extending the chiller operation. Additionally, for thermal solar cooling, the hot water tank between the solar field and the chiller [10] plays the fundamental role of limiting fluctuations in solar radiation with respect the PV-based due to the grid connection.

Furthermore, an important aspect to consider during a solar cooling design is the operating conditions, in particular the influence of the ambient temperature. The heat rejection system affects the whole plant performance in close circuits [11] whilst the open circuit suffers from the tropical climate as proposed by Muzaffar et al. [12].

Despite the large number of works addressing the plant simulation, a limited number of studies include the interaction between plant and building as proposed by Ma and Guan [13] and in the authors' previous researches.

This paper proposes the analysis of a solar cooling system to meet the cooling requirement of an office building. After determining the demand profile, the behavior of four solar cooling technologies (absorption chiller, adsorption chiller, DEC system and PV with compression chiller) is evaluated for three different environmental conditions, referring to three selected locations: Abu Dhabi, Riyadh and Palermo.

\section{Models and methods}

The work deals with determining the best solar cooling solution coupled with a large office building. In the paper, four different solar cooling technologies are analyzed, providing the same output ( $70 \%$ of the annual load), and optimized with the objective of minimizing the installation cost. The annual solar fraction of $70 \%$ represents an important achievement in terms of energy saving without force the system to reach a higher solar fraction with a detrimental impact on the installation cost [14]. The evaluation has been made by annual transient simulation under the real operating conditions of three locations: Riyadh (KSA), Abu Dhabi (UAE), and Palermo (IT). The weather data included in the models are provided by the Meteonorm database [15] characterized by accurate and reliable information. The main ambient conditions are reported in figure 1 and in figure 2. Abu Dhabi shows a high level of humidity, that affect the solar source, coupled with high air temperature and represents the worst combination of ambient conditions. In contrast, Riyadh exhibits typical very dry desert conditions and high direct solar radiation. Differently, Palermo presents a combination of high relative humidity, higher than Abu Dhabi, and lowest temperature among the proposed location according the lower latitude.

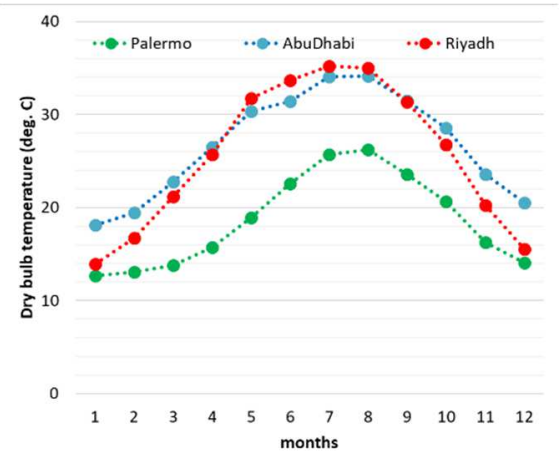

(a)

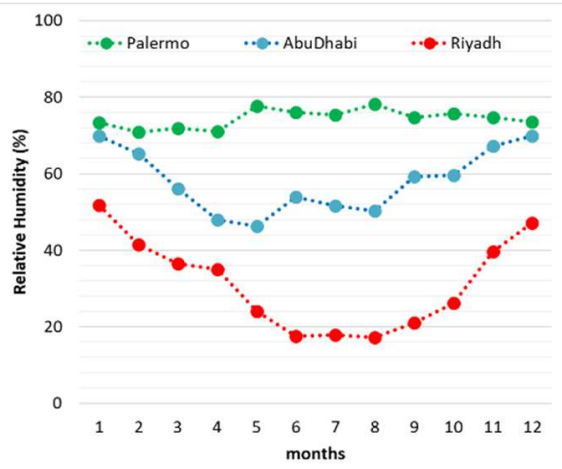

(b)

Fig. 1. Monthly average temperature (a) and humidity (b) 


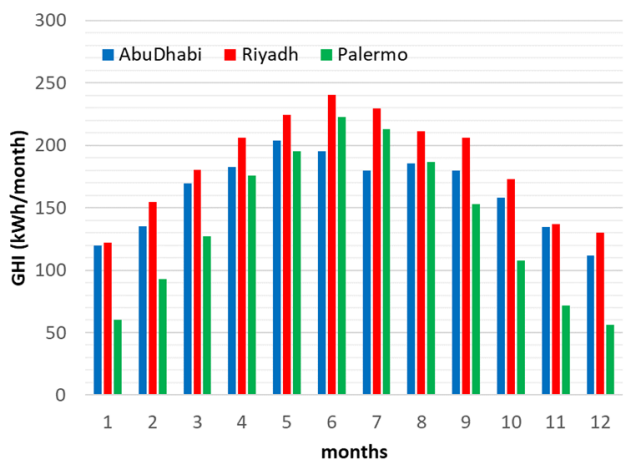

(a)

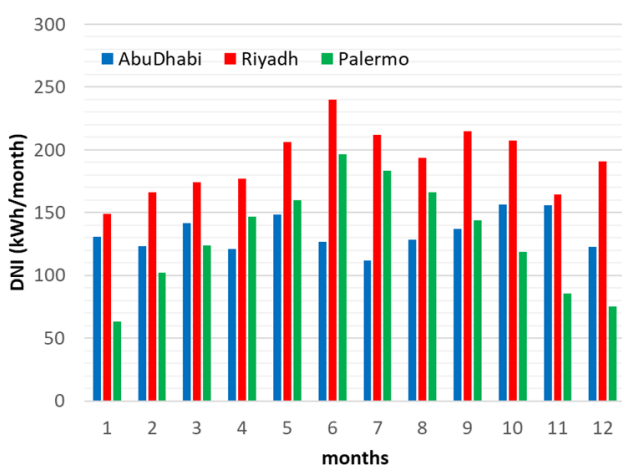

(b)

Fig. 2. Monthly available irradiance GHI (a) and DNI (b)

\subsection{Tertiary office building}

A tertiary office building represents a common application in new financial districts in the Middle East regions. A detailed model has been developed in Trnsys 18 [16] coupled with SketchUp software and Trnsys3D plug-in [17] for the architectural aspects of the building. The total area of $2200 \mathrm{~m}^{2}$ was designed according to the Dubai Green-Building Regulation and Specifications; in addition, the requirements of Passiv Haus Institutes [18] [19] and the main features of Dubai Autonomous Building [20] were met. The main aspects of the considered internal load are reported in Table 1. The internal load of a complex building includes occupancy, lights, and appliances distribution in the different rooms. The detailed annual transient simulation considers random overload events related to conferences and meetings.

Table 1. Internal loads and comfort specifications

\begin{tabular}{|l|c|c|}
\hline Temperature set point & ${ }^{\circ} \mathrm{C}$ & 22 \\
\hline Relative humidity set point & $\%$ & 50 \\
\hline Air changes & $\mathrm{m}^{3} / \mathrm{h}$ & 3500 \\
\hline Recuperative HX effectiveness & $\%$ & 67 \\
\hline Infiltration & $\mathrm{Vol} / \mathrm{h}$ & 0.1 \\
\hline Lighting (peak) & $\mathrm{W} / \mathrm{m}^{2}$ & 19 \\
\hline Internal gains (peak) & $\mathrm{kW}$ & 100 \\
\hline Occupancy (max) & $\mathrm{Nr}$. & 350 \\
\hline
\end{tabular}

The building cooling demand has been computed in a transient analysis on annual basis under the ambient conditions of the three selected locations. The modeling and the simulation have been performed according to the procedure proposed in [21], and a summary of the cooling load is listed in Table 2 in terms of peak and annual load, dividing the sensible and latent components.

The office building simulation results are reported in terms of monthly cooling load in figure 3. The reported trend shows that the Abu Dhabi condition is the most critical among the selected locations due to the high temperature and humidity levels. The sensible cooling load is very similar for the two Middle Eastern locations, while the latent load is much higher for Abu Dhabi where it accounts for $40 \%$ of the annual requirement. The Mediterranean region requires a rather high latent load, increasing the overall cooling demand, despite the lower temperature compared to Riyadh. 


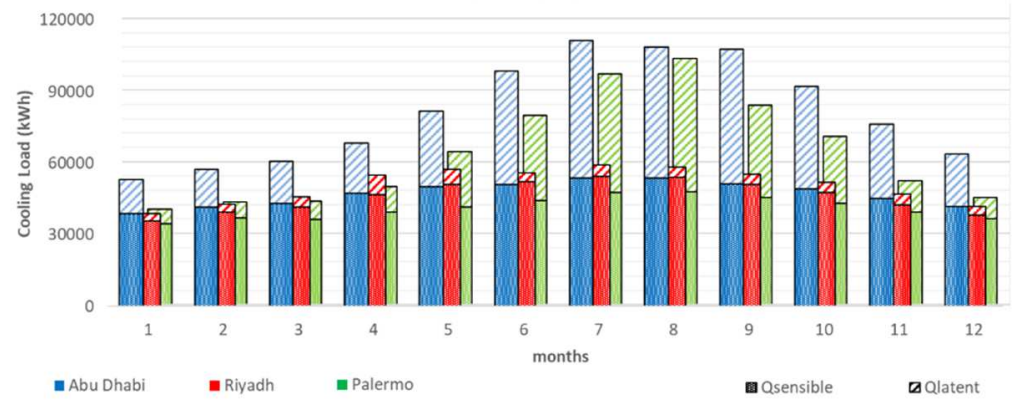

Fig. 3. Building monthly cooling load

Table 2. Cooling load a single building (Global - Sensible)

\begin{tabular}{|c|c|c|c|}
\hline Cooling load & Abu Dhabi & Riyadh & Palermo \\
\hline Peak cooling load $(\mathrm{kW})$ & $256-126$ & $159-125$ & $239-115$ \\
\hline Annual cooling load $(\mathrm{GWh})$ & $980-567$ & $609-555$ & $771-487$ \\
\hline
\end{tabular}

\subsection{Solar cooling system}

The cooling loads evaluate in the previous paragraph were adopted as input for the cooling plants. Proposed plant solutions are based on market availability and component performance under design and off-design conditions is evaluated from operating maps provided by the manufacturer. The work proposes a comparison between four different solar cooling technologies: two solar thermal cooling systems ( $\mathrm{Li}-\mathrm{Br}$ absorption and adsorption chiller), solar Desiccant Evaporative Cooling (DEC) system and solar electric cooling (compression chiller). The vapor compression chiller is the only electrical-powered technology and connected with a field of photovoltaic modules. The solar thermal and desiccant evaporative cooling systems are powered by a solar field of Evacuated Tube Collectors (ETC). The collector control includes a variable speed pump that modulates the water flow passing the solar field with the aim of keeping the outlet temperature closed to the chiller hot source temperature set point. The evacuated tube collector efficiency is evaluated according to the quadratic efficiency equation (1) with the parameters reported in Tab. 3. ( $\bar{T}=$ mean temperature between inlet and outlet of the collector and BTI represents the direct radiation incident on the titled surface).

$$
\eta=a_{0}-a_{1} \frac{\bar{T}-T_{a m b}}{B T I \cdot C R}-a_{2} \frac{\left(\bar{T}-T_{a m b}\right)^{2}}{B T I \cdot C R}
$$

The specifications of the solar fields are listed in Table 3 and the chiller technical data are listed in Table 4 and table 5.

Table 3. Solar fields specifications

\begin{tabular}{|c|c|c|c|c|c|}
\hline \multicolumn{3}{|c|}{ Solar Field $(\boldsymbol{E T C})$} & \multicolumn{3}{c|}{ Solar Field (PV) } \\
\hline Outlet set point temperature* & ${ }^{\circ} \mathrm{C}$ & 105 & Maximum power (Pmax) & $\mathrm{W}$ & 250 \\
\hline Concentration ratio (CR) & - & 1 & Module efficiency $(\eta \mathrm{m})$ & $\%$ & 14.91 \\
\hline Optical efficiency (a) & - & 0.718 & Temperature coefficient Isc & $\% /{ }^{\circ} \mathrm{C}$ & 0.051 \\
\hline $1^{\text {st }}$ heat loss coeff. (a $)$ & $\mathrm{W} / \mathrm{m}^{2} / \mathrm{K}$ & 0.974 & Temperature coefficient Uoc & $\% /{ }^{\circ} \mathrm{C}$ & -0.31 \\
\hline $2^{\text {nd }}$ heat loss coeff. (a $)$ & $\mathrm{W} / \mathrm{m}^{2} / \mathrm{K}^{2}$ & 0.005 & Temperature coefficient Pmpp & $\% /{ }^{\circ} \mathrm{C}$ & -0.41 \\
\hline * Rated solar field outlet temperature: $95^{\circ} \mathrm{C}$ for $1 \mathrm{sABS}, 85^{\circ} \mathrm{C}$ for ADS, 80 for DEC \\
\hline
\end{tabular}


Table 4. Li-Br absorption chiller parameters and Adsorption Chiller parameters

\begin{tabular}{|c|c|c|c|c|c|}
\hline \multicolumn{2}{|c|}{ Li-Br Absorption Chiller } & \multicolumn{3}{c|}{ Adsorption Chiller } \\
\hline & unit & value & & unit & value \\
\hline Rated COP & - & 0.75 & Rated COP & - & 0.60 \\
\hline Hot source range & ${ }^{\circ} \mathrm{C}$ & $90-115$ & Hot source range & ${ }^{\circ} \mathrm{C}$ & $80-95$ \\
\hline Design chilled water & ${ }^{\circ} \mathrm{C}$ & $12-7$ & Design chilled water & ${ }^{\circ} \mathrm{C}$ & $14-9$ \\
\hline Design hot water & ${ }^{\circ} \mathrm{C}$ & $98-88$ & Design hot water & ${ }^{\circ} \mathrm{C}$ & $79-85$ \\
\hline Design cooling water & ${ }^{\circ} \mathrm{C}$ & $30-37$ & Design cooling water & ${ }^{\circ} \mathrm{C}$ & $31-35$ \\
\hline
\end{tabular}

Table 5. Vapor compression chiller parameters and Desiccant Evaporative

\begin{tabular}{|c|c|c|c|c|c|}
\hline \multicolumn{3}{|c|}{ Desiccant Evaporative } & \multicolumn{3}{c|}{ Compression Chiller } \\
\hline & unit & value & & unit & value \\
\hline Rated COP & - & 0.46 & Rated COP & - & 5.65 \\
\hline Design fresh air temp & ${ }^{\circ} \mathrm{C}$ & $30-50$ & Design Energy Input & $\mathrm{kW}$ & 215 \\
\hline Design exhaust air temp & ${ }^{\circ} \mathrm{C}$ & $72-43$ & Design chilled water & ${ }^{\circ} \mathrm{C}$ & $12-7$ \\
\hline Hot source range & ${ }^{\circ} \mathrm{C}$ & $50-92$ & Design cooling water & ${ }^{\circ} \mathrm{C}$ & $35-30$ \\
\hline Air changes & $\mathrm{m}^{3} / \mathrm{h}$ & 8200 & & & \\
\hline
\end{tabular}

The heat rejection systems represent a crucial point for the chiller performance as reported in [22]: the cooling tower, which has proved to be the most favorable and economical solution, is adopted in the models, except for the solution with the DEC that does not require a heat sink.

Moreover, all the technologies are equipped with an auxiliary system that supply to the plant the primary energy (thermal or electric) when the solar source is not enough.

The adopted thermal solar cooling layout is reported in figure 4 and is based on a standard solution for this technology [23]. To improve the cooling efficiency, a storage system with two tanks is adopted (vertical cylinder, stratified): the hot storage, between the solar field and the chiller, reduces the solar radiation fluctuation, while the cold storage, with half the volume of the hot one, between the chiller and building, allows a continuous chiller operation close to the design conditions. The model includes an auxiliary chiller that is activated when the hot tank is empty or the solar system is not enough.

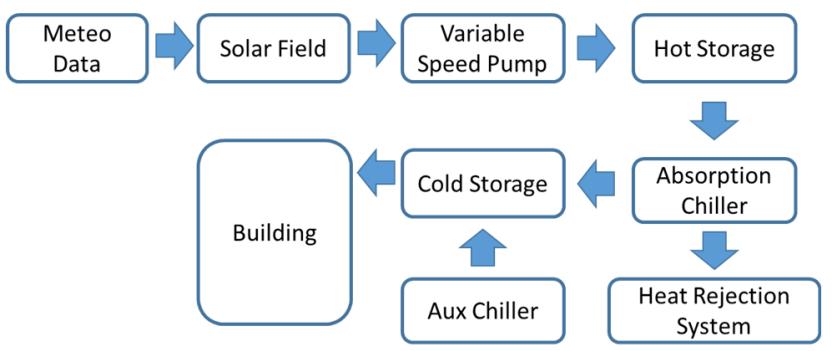

Fig. 4. Schematization of the thermal solar cooling systems (absorption and adsorption)

The DEC operates in ventilation configuration as shown in Fig. 5 and represents the most common layout as demonstrated by Tobias Bader et al. [24]. A detailed explanation of the desiccant evaporative is reported in [25] and the main parameter are reported in table 5. The air 
flow is drawn in from outside and passing through the lower part of the desiccant wheel is dehumidified; then, the temperature is lowered in an air-to-air heat exchanger and finally with the evaporative cooling, also adjusting the humidity level. In this way, the air flow is brought to the required comfort conditions inside the building. The exhaust air leaving the building is first saturated by the humidification process; then, it is used to cool the incoming fresh air and for the regeneration of the desiccant wheel. Solar contribution allows exhaust air to increase the temperature level up to $80^{\circ} \mathrm{C}$ before entering the rotor. An auxiliary vapor compression chiller, coupled with a heat exchanger on the fresh air stream, powered by the grid, provides a cooling effect when the DEC system is not able to keep temperature or humidity at the set points.

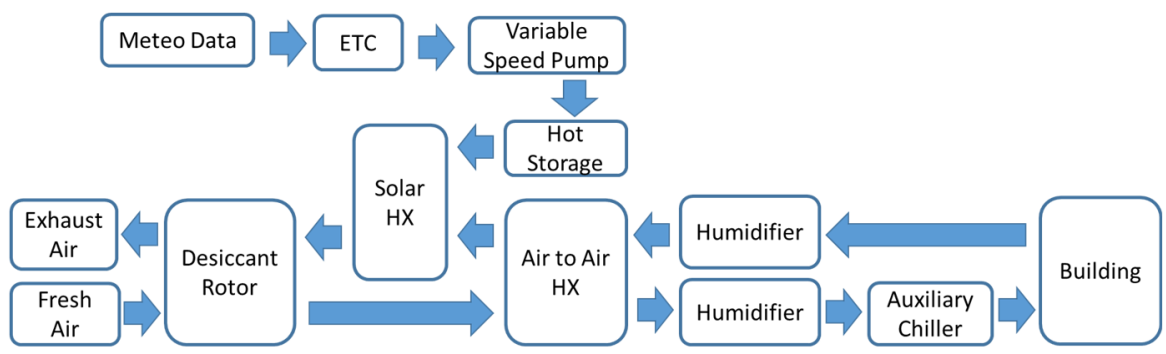

Fig. 5. Schematization of the solar desiccant evaporative cooling

Finally, the vapor compression chiller represents the most common solution for both industrial and residential applications. The selected layout is reported in figure 6. Starting from the manufacturer specification (reported in Table 5), the chiller performances are evaluated with partial load and off design temperature according to the heat rejection system. The national grid is adopted as a backup unit, to absorb excess energy when the batteries have reached maximum capacity and to provide power to the refrigeration machine when the production from PV is not adequate to meet the load.

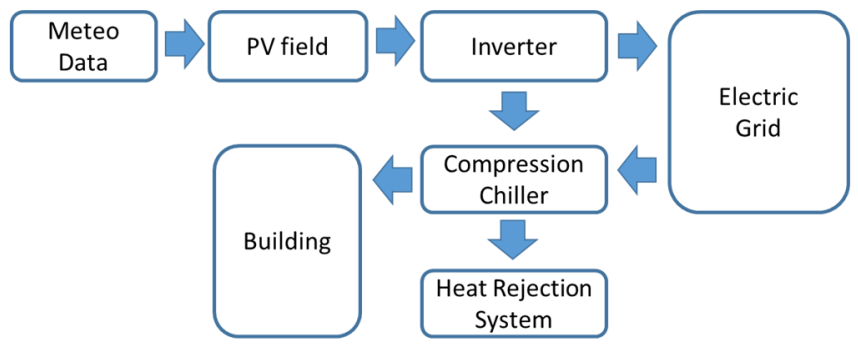

Fig. 6. Schematization of the solar cooling systems

The annual solar fraction is evaluated as reported in equation (2) as the annual amount of renewable energy provided from the solar cooling system with respect to the global cooling energy as the sum of renewable cooling energy and auxiliary chiller energy. For the electrical solar cooling the evaluation (Eq. 3) has been made on the grid balances between PV selfconsumption and chiller electric load.

$$
\begin{gathered}
S F=\frac{Q_{a b s}}{Q_{a b s}+Q_{a u x}}=\frac{Q_{a d s}}{Q_{a d s}+Q_{a u x}}=\frac{Q_{D E C}}{Q_{D E C}+Q_{a u x}} \\
S F=\frac{E_{P V}-\text { export }}{E_{\text {chiller }}}=\frac{E_{\text {chiller }}-\text { import }}{E_{\text {chiller }}}
\end{gathered}
$$




\subsection{Optimization}

The solar cooling plants are designed and optimized to achieve the selected annual solar fraction of 70\%; the residual load is supposed covered by the auxiliary energy source (thermal or electrical)/system according to the technology. The optimization has been performed using the software GenOpt, developed by the Berkley University. The algorithm launch several annual Trnsys simulations, following a research grid, with the aim of minimizing an optimization function [26]. The research space is reported in Table 6 for the solar field aperture area and the energy storage size (the volume of the TES and the capacity of the battery). The design capacity of the chiller is selected according to the following criteria: equal to $70 \%$ of peak load for absorption and adsorption chillers due to the adoption of two tank layout and equal to $100 \%$ of peak load for desiccant evaporative and compression chillers. The chiller capacities, according to the demand for each location, are reported in Table 7.

The optimization function, specifically, the budget cost of the plant, includes a penalty function that rejects the solution that does not achieve the minimum solar fraction. The objective functions, for all layouts, are reported in the equation from (4) to (7). The budget cost accounts: solar filed (PV or ETC), chiller systems (ABS, ADS, DEC or CC), and the storage systems (thermal or electrical). The optimization process is based on a two-step procedure coupling the particle swarm algorithm (first step) with the Hooke and Jeeves algorithm (second step), in order to improve the local and global optimum selection. The capital expenditure is estimated as the sum of the main components, the adopted cost values, listed in Table 8, are provided by manufacturers, technical reports and open literature for both the thermal [27] and for the electrical part [28] [29].

$$
\begin{aligned}
& f_{\text {min }}=A_{E T C} \cdot \operatorname{Cost}_{E T C}+\operatorname{Cap}_{A b s} \cdot \operatorname{Cost}_{A b s}+\operatorname{Vol}_{\text {tank }} \cdot \operatorname{Cost}_{\text {tank }}+\text { Penalty }_{(S F<0.70)} \\
& f_{\text {min }}=A_{E T C} \cdot \operatorname{Cost}_{E T C}+\operatorname{Cap}_{A d s} \cdot \operatorname{Cost}_{A d s}+\operatorname{Vol}_{\text {tank }} \cdot \operatorname{Cost}_{\text {tank }}+\text { Penalty }_{(S F<0.70)} \\
& f_{\text {min }}=A_{E T C} \cdot \operatorname{Cost}_{E T C}+\operatorname{Cap}_{D E C} \cdot \operatorname{Cost}_{D E C}+\operatorname{Vol}_{\text {tank }} \cdot \operatorname{Cost}_{\text {tank }}+\text { Penalty }_{(S F<0.70)} \\
& f_{\text {min }}=A_{P V} \cdot \operatorname{Cost}_{P V}+\operatorname{Cap}_{C C} \cdot \operatorname{Cost}_{C C}+\operatorname{Cap}_{\text {battery }} \cdot \text { Cost }_{\text {battery }}+\text { Penalty }_{(S F<0.70)}
\end{aligned}
$$

Table 6. Optimization variables (minimum value - maximum value)

\begin{tabular}{|c|c|c|c|c|}
\hline & & Abu Dhabi & Riyadh & Palermo \\
\hline Collectors area & $\mathrm{m}^{2}$ & $500-4000$ & $200-1000$ & $400-2500$ \\
\hline Hot storage & $\mathrm{m}^{3}$ & $20-800$ & $10-200$ & $0-450$ \\
\hline Battery capacity & $\mathrm{kWh}$ & $0-300$ & $0-120$ & $0-200$ \\
\hline
\end{tabular}

Table 7. Chiller capacity

\begin{tabular}{|c|c|c|c|c|}
\hline & & Abu Dhabi & Riyadh & Palermo \\
\hline $100 \%$ peak load & $\mathrm{kW}$ & 256 & 160 & 240 \\
\hline $70 \%$ peak load & $\mathrm{kW}$ & 179 & 111 & 167 \\
\hline
\end{tabular}


Table 8. Budget costs

\begin{tabular}{|c|c|c|}
\hline \multicolumn{3}{|c|}{ Collectors } \\
\hline Evacuated Tube Collectors & $\mathrm{USD} / \mathrm{m}^{2}$ & 500 \\
\hline Photovoltaic & USD/kW & 1100 \\
\hline \multicolumn{3}{|c|}{ Storage } \\
\hline Hot Water Tank & $\mathrm{USD} / \mathrm{m}^{3}$ & 450 \\
\hline Chilled Water Tank & $\mathrm{USD} / \mathrm{m}^{3}$ & 450 \\
\hline Electric Energy Storage & USD $/ \mathrm{kWh}$ & 510 \\
\hline \multicolumn{3}{|c|}{ Chiller } \\
\hline Li-Br 1s Absorption Chiller & $\mathrm{USD} / \mathrm{kW}$ & 400 \\
\hline Adsorption Chiller & $\mathrm{USD} / \mathrm{kW}$ & 450 \\
\hline Desiccant Evaporative Cooling & $\mathrm{USD} / \mathrm{kW}$ & 320 \\
\hline Vapor Compression Chiller & USD /kW & 150 \\
\hline
\end{tabular}

\section{Results and Discussion}

\subsection{Optimization results}

The optimization procedure selects the best components sizing under the previously described restrictions. The optimization results are shown in figure 7 where solar field aperture area, storages sizing, and chiller rated capacity have been reported. The first information highlighted is that the solar desiccant evaporative, in Abu Dhabi, does not reach the selected solar fraction: the high humidity and ambient temperature, combined with a low temperature set point, limit the operation of the system. The DEC solution in Abu Dhabi is discarded and then in the following figures, the related values are crossed by a red bar.

The trend shows a considerable increase in component size moving from low to higher efficiency technologies in terms of design COP. In particular, the trend is significant for absorption and adsorption chillers. The adsorption chiller solution requires a greater area of solar aperture, emphasizing a greater impact of the lower radiation available in Palermo. The desiccant evaporative shows the worst performance especially with high humidity, whereas the condition of Riyadh makes all technologies comparable. The compression chiller coupled to the cooling tower represents an energy-efficient solution; however, the required solar field is quite larger with respect to thermal solar cooling solution because it is based on a less efficient technology (15\% of PV modules vs. $70 \%$ of ETC). Furthermore, the solar field shows a different rate of increases between the locations. The trend of Abu Dhabi aperture area highlights the critical off-design operation of chiller and heat rejection system whilst, the Riyadh meteo conditions allow better renewable source exploitation. 


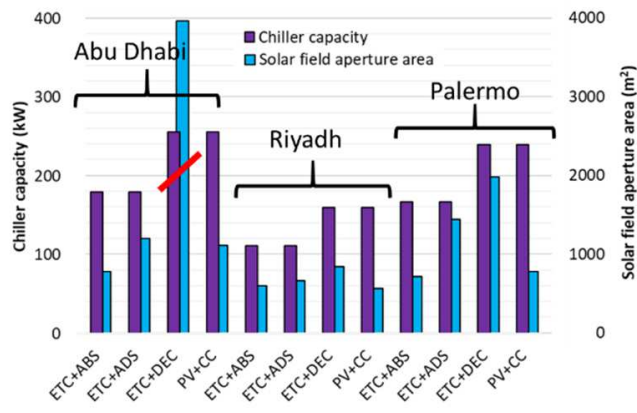

(a)

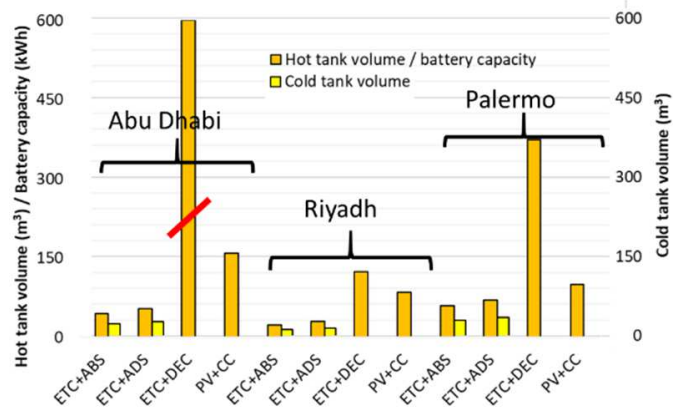

(b)

Fig. 7. Optimization results - components sizing: chiller capacity and solar field aperture area (a), hot tank volume, battery capacity and cold tank volume

The storage, reported in $\mathrm{m}^{3}$ for hot water tank and $\mathrm{kWh}_{\mathrm{e}}$ for electric batteries, shows a similar sizing for absorption chiller and adsorption chiller, while, for the desiccant evaporative solution a 4 times larger volume is required due to the different operation and the different physical process. Furthermore, the storage capacity, in terms of cooling energy stored, as reported in figure 8 , shows the energy equivalence between the thermal solar cooling and electrical solar cooling. The storages capacity are evaluated according the design values of TES (volume and temperature) and chiller (COP, mass flow rate and inlet/outlet temperature).

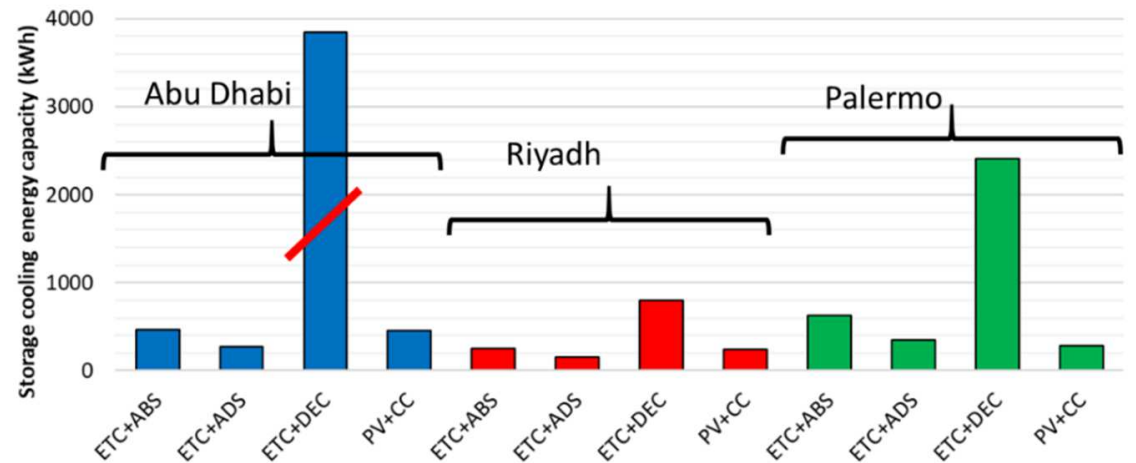

Fig. 8. Storage capacity in terms of cooling energy stored (design values)

\subsection{Solar cooling system performance}

The optimum solution has been simulated over a one-year operation. As example, detailed analysis of the three-day operation is shown in figure 9, under the Abu Dhabi climate condition, for adsorption chiller and vapor compression chiller respectively. The plot shows the main parameters of the plants in summer operation: precisely the last part of July that represents the worst operation condition. The black dashed line represents the cooling load of the adsorption chiller and the electric load of the compression chiller.

The right part of the chart (fig. 9a) shows the operation of the adsorption chiller-based plant. The dotted lines represent the top and the bottom temperature of the hot tank, the storage is recharged during sunny hours and drained in the evening. The hot tank temperature affects the adsorption chiller cooling production that shows a consistent reduction. Due to the off-design operation. The last part of the night/early morning is covered by a limited on-off operation of the auxiliary chiller reported in a violet line. 
The left part of the figure highlights the electric exchanges between the components. The Blue line represents the electric power export required when the battery capacity is fulfilled and the load is satisfied (typically in central hours). On the contrary, the yellow line represents the power import necessary to cover part of the night load. The red dotted line (battery state of charge) shows the large operation of the electric storage in order to satisfy the daily demand. Both of the systems proposed in the chart show a good operation in daily and annual cooling production. The load is completely satisfied most of the time and the annual solar cooling achieved is equal to $70 \%$.

Figure 10 and figure 11 show, respectively, for the same three days, the behavior of the abovedescribed systems under the weather conditions of Riyadh and Palermo. The charts highlight the influence of the ambient conditions, especially for the adsorption-based system, on the daily operation. The solar source availability in Riyadh forces the control system to continuously switch on and off the solar field pump as underlined by the green line oscillations. On the contrary, under Palermo conditions, the source is better exploited due to the limited solar radiation and the lower ambient temperature. The capacity of the hot tank appears oversized by the slow degradation of the temperature, the severe condition of Palermo has forced the optimization to select larger storages and, as consequence, in summer day the storage is fulfilled and ensure an uninterrupted operation of the adsorption chiller with a limited integration from the auxiliary chiller.

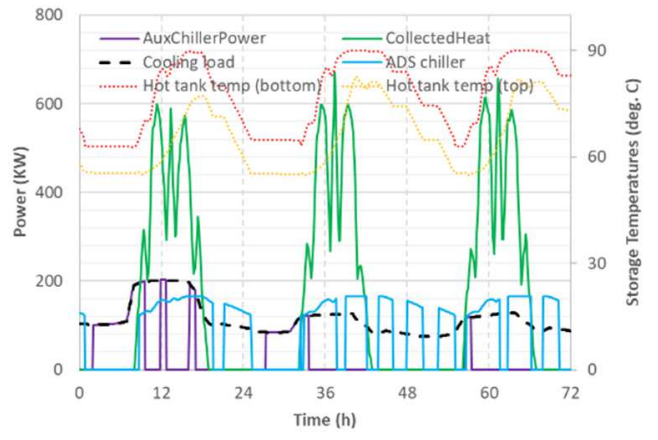

(a) Adsorption chiller

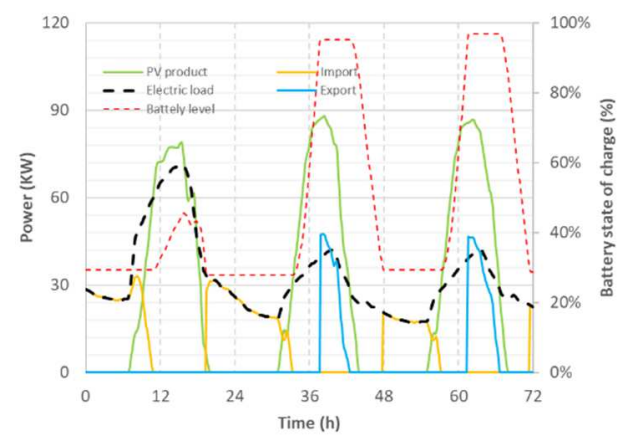

(b) Compression chiller

Fig. 9. Solar cooling plant simulation comparison in summer days (Abu Dhabi, UAE)

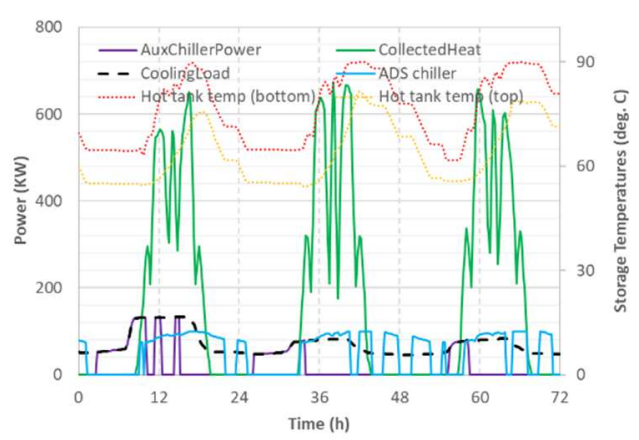

(a) Adsorption chiller

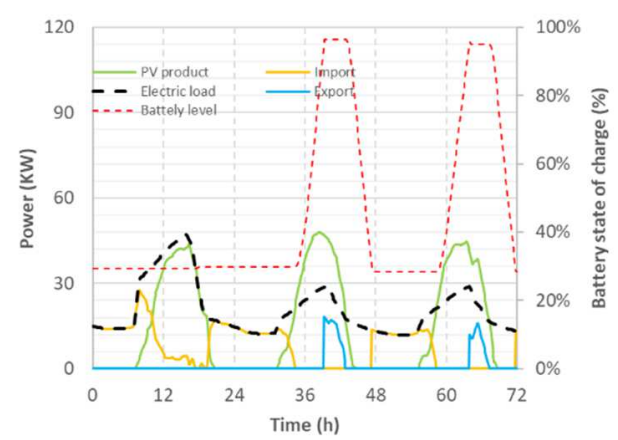

(b) Compression chiller

Fig. 10. Solar cooling plant simulation comparison in summer days (Riyadh, KSA) 


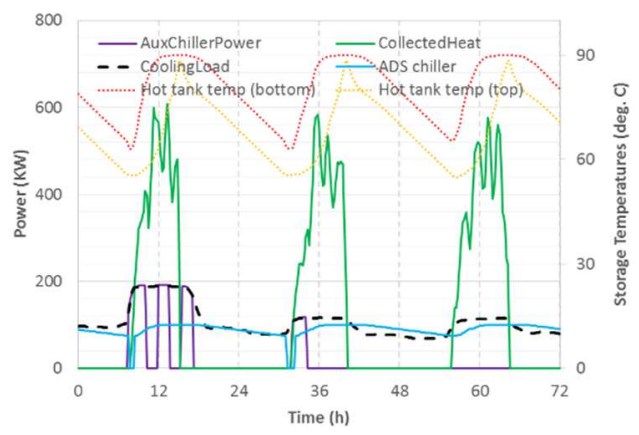

(a) Adsorption chiller

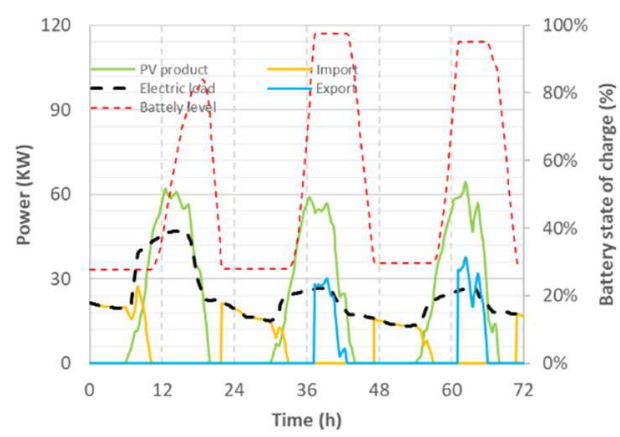

(b) Compression chiller

Fig. 11. Solar cooling plant simulation comparison in summer days (Palermo, ITA)

\subsection{Economic consideration}

Moving to the economic comparison, the results confirm the technical considerations. The bar chart, shown in figure 12, reports the consistent investment related to the solar field that, in some cases represents $80 \%$ of the capital expenditure. Similarly, the figure 13, lists the cost of the main components. For solar thermal cooling at the same location, the lower efficiency of the chiller causes the relative cost of the solar array to increase more than the other components. Furthermore, in Riyadh, the cost of the storage, and its volume, are similar for ABS and ADS. Differently, in Abu Dhabi and Palermo, the installation cost difference between solar thermal cooling systems is significant.

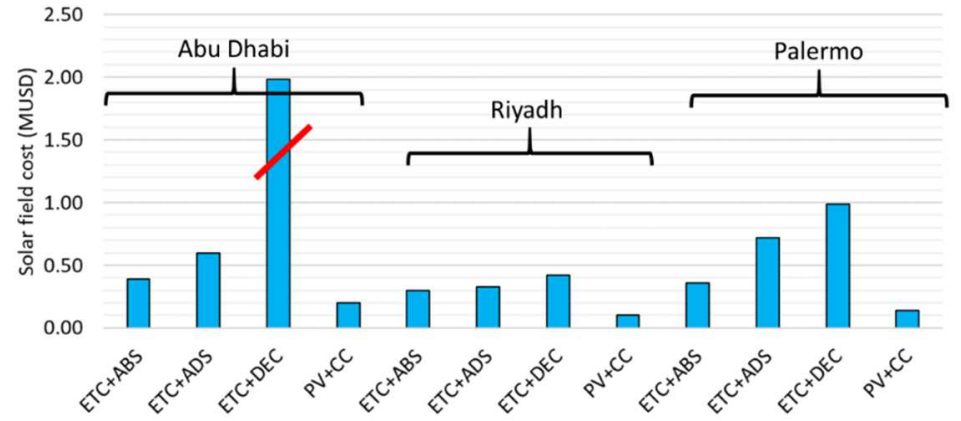

Fig. 12. Solar field cost

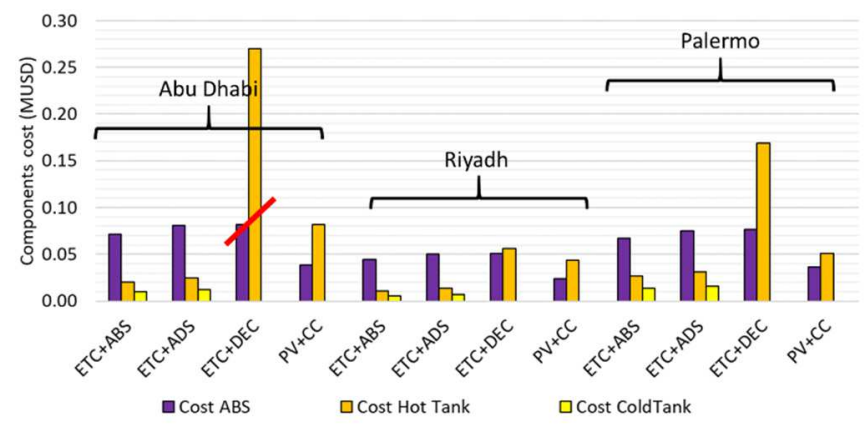

Fig. 13. Solar cooling systems components cost 
Finally, the global installation costs of the cooling plants are compared in figure 14 . The trend shows the unsustainability of the DEC solution for high temperature and humidity climate whilst, in a dry region, the cost is comparable. The difference between absorption chiller and adsorption chiller is highlighted by seaside location (low radiation and high humidity) more than from lower ambient temperature as underlined from the Palermo result. The electric-based solution, despite the high storage cost, represents the more cost-effective layout. The photovoltaic global production has driven a consistent cost reduction of the technology that, in recent years, half the cost of the modules.

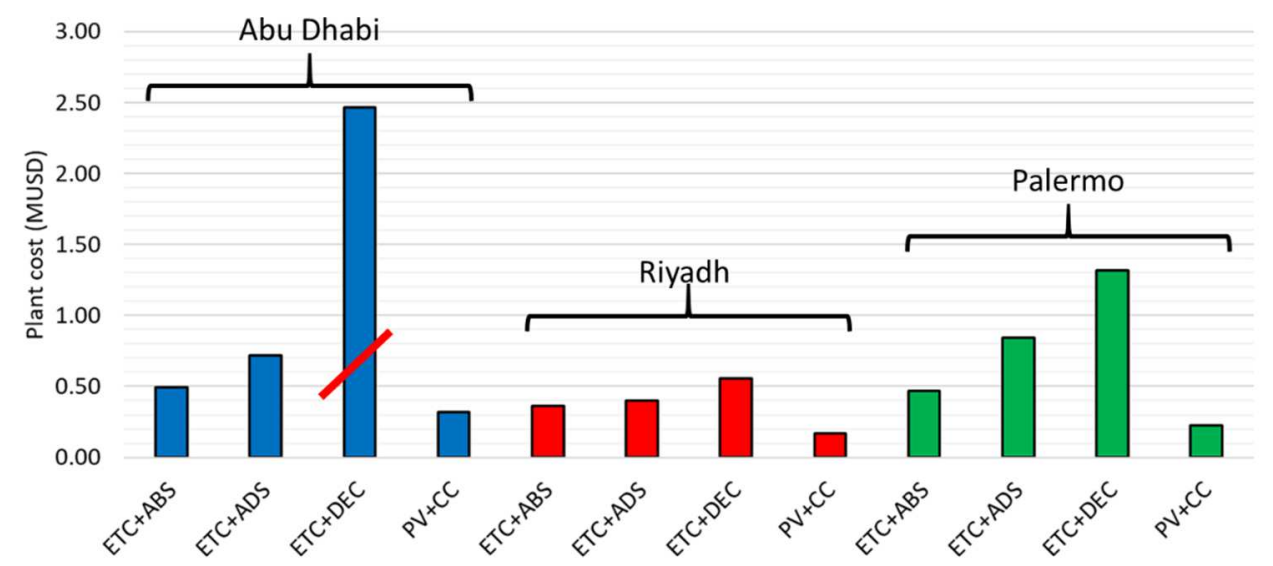

Fig. 14. Solar cooling installation costs

\section{Conclusions}

The work presents a comparison between four different solar cooling technologies in three different locations, among hot climates in the MENA region (Riyadh, KSA, and Abu Dhabi, UAE) and South Italy (Palermo). The paper includes the complete modelling and simulation of a new office building, designed according to the lowest energy reduction standard, to perform the cooling demand under different ambient conditions. The cooling load required from the office building was satisfied at $70 \%$, on annual basis, from the solar cooling systems and the residual load from the auxiliary chiller. The solar cooling systems are selected among the most efficient and reliable technologies available: two solar thermal cooling (Evacuated Tube Collectors + Li$\mathrm{Br}$ absorption chiller + thermal storages and ETC + adsorption chiller + thermal storages), a Solar Desiccant Evaporative Cooling (ETC + DEC + thermal storage) and, an electric solar cooling (PV + electric energy storage + compression chiller). The performance of each solution was evaluated in transient simulation under variable operating conditions for a 1-year period. A multivariable optimization of the minimum budget cost of the plant selects the optimal size of the components under the imposed solar fraction constraint. The optimization results show that the desiccant evaporative, in Abu Dhabi, due to the high relative humidity, and the critical operation parameters, does not achieve the selected solar fraction. Solar thermal cooling highlights large capability in terms of cooling production and cost-effectiveness. Electric solar cooling, thanks to the lower cost of components and commercial availability, represents the best solution both in terms of technical efficiency and installation cost. It has been demonstrated that the introduction of a storage system, regardless of the solution adopted, is the only way to achieve the large integration of renewable, required by new energy systems. Solar thermal cooling coupled with hot water storage appears to be very affordable, however, limited efficiency of chillers rewards compression chiller coupled with high cost electric storage. 
Nomenclature

\begin{tabular}{|c|l|c|l|}
\hline & acronyms & $R H$ & Relative humidity \\
\hline$A$ & Solar field aperture area & $S F$ & Solar fraction \\
\hline$A B S$ & Absorption chiller & $T_{a m b}$ & Ambient temperature \\
\hline$A D S$ & Adsorption chiller & $\bar{T}$ & $\begin{array}{l}\text { Mean temperature between inlet and } \\
\text { outlet of the collector }\end{array}$ \\
\hline$A u x$ & Auxiliary compression chiller & $T E S$ & Thermal energy storage \\
\hline$B T I$ & Beam tilted irradiance & $V o l$ & $T E S$ volume \\
\hline Cap & Component design capacity & & subscripts \\
\hline$C C$ & Compression chiller & $A u x$ & Auxiliary compression chiller \\
\hline$C O P$ & Coefficient of performance & $E T C$ & Evacuated Tube Collectors \\
\hline Cost & Component unit cost & chiller & Auxiliary chiller \\
\hline$C R$ & Concentration ratio & $S F<70$ & Solar fraction under the limit \\
\hline$D E C$ & Desiccant evaporative cooling & $t a n k$ & TES storage \\
\hline DNI & Direct normal irradiance & $A b s$ & Absorption chiller \\
\hline$E$ & Annual electric energy & $A d s$ & Adsorption chiller \\
\hline$E T C$ & Evacuated Tube Collectors & $D E C$ & Desiccant evaporative cooling \\
\hline export & Annual electric energy export & $C C$ & Compression chiller \\
\hline$f_{m i n}$ & Optimization function & $B a t t e r y$ & Electric energy storage \\
\hline$G H I$ & Global horizontal irradiance & $P V$ & Photovoltaic \\
\hline$H X$ & Heat exchanger & & symbols \\
\hline import & Annual electric energy import & $a_{0}$ & Optical efficiency \\
\hline$M E N A$ & Middle East and North Africa & $a_{1}$ & $1^{\text {st }}$ order heat loss coefficient \\
\hline Penalty & Penalty factor & $a_{2}$ & $2^{\text {nd }}$ order heat loss coefficient \\
\hline$P V$ & Photovoltaic & $\eta$ & Evacuated tube collectors efficiency \\
\hline$Q$ & Annual cooling energy & & \\
\hline
\end{tabular}

\section{References}

1. V. Eveloy and D. S. Ayou, Energies 12, (2019)

2. A. A. Al-Ugla, M. A. I. El-Shaarawi, and S. A. M. Said, Int. J. Refrig. 53, 90 (2015)

3. A. Al-Alili, Y. Hwang, and R. Radermacher, Int. J. Refrig. 39, 4 (2014)

4. J. Guo, J. I. Bilbao, and A. B. Sproul, Renew. Energy 162, 1273 (2020)

5. E. Aridhi, H. Bemri, and A. Mami, 3 (n.d.)

6. L. Huang and R. Zheng, Buildings 8, (2018)

7. C. Luerssen, H. Verbois, O. Gandhi, T. Reindl, C. Sekhar, and D. Cheong, Appl. Energy 286, (2021)

8. L. Goldie-Scot, BloombergNEF 1 (2019)

9. R. Fu, T. Remo, R. Margolis, R. Fu, T. Remo, and R. Margolis, 2018 U . S . UtilityScale Photovoltaics- Plus-Energy Storage System Costs Benchmark (2018)

10. A. Al-Alili, Y. Hwang, R. Radermacher, and I. Kubo, Sol. Energy 84, 2034 (2010)

11. A. Lecuona, R. Ventas, C. Vereda, and R. López, Appl. Therm. Eng. 79, 140 (2015)

12. M. Ali, V. Vukovic, N. A. Sheikh, and H. M. Ali, Energy Convers. Manag. 97, 323 (2015)

13. Y. Ma and L. Guan, Procedia Eng. 121, 528 (2015)

14. U. Eicker, D. Pietruschka, M. Haag, and A. Schmitt, Energy Procedia 57, 2581 (2014)

15. J. Remund, S. Müller, S. Kunz, and C. Schilter, Meteonorm Handbook Part II: Theory (2012) 
16. T. P. McDowell, D. E. Bradley, M. Hiller, J. Lam, J. Merk, and W. Keilholz, Build. Simul. Conf. Proc. 4, 2049 (2017)

17. M. C. Murray, N. Finlayson, M. Kummert, and J. Macbeth, IBPSA 2009 - Int. Build. Perform. Simul. Assoc. 20091389 (2009)

18. P. H. Institute, Passiv. House Inst. 1 (2016)

19. Brian Ford, R. Schiano-Phan, and D. Zhongcheng, THE PASSIVHAUS STANDARD IN EUROPEAN WARM CLIMATES: DESIGN GUIDELINES FOR COMFORTABLE LOW ENERGY HOMES (2007)

20. G. Brumana, G. Franchini, and A. Perdichizzi, Energy Procedia 126, 155 (2017)

21. G. Franchini, G. Brumana, and A. Perdichizzi, Energy Build. 205, 109545 (2019)

22. G. Brumana, G. Franchini, E. Ghirardi, and A. Perdichizzi, E3S Web Conf. 197, (2020)

23. A. Shirazi, R. A. Taylor, S. D. White, and G. L. Morrison, Renew. Energy 86, 955 (2016)

24. T. Bader, S. Brandmayr, C. Trinkl, W. Zörner, and V. Hanby, Energy Procedia 48, 778 (2014)

25. G. Brumana and G. Franchini, Energy Procedia 101, 288 (2016)

26. M. Wetter, Proc. IBPSA's Build. Simul. 2001 Conf. August 13-15, 2001 Rio Janeiro 9 (2001)

27. IEA-ETSAP and IRENA, Thermal Energy Storage-Technology Brief E17 (2013)

28. R. Fu, D. Feldman, and R. Margolis, Nrel 1 (2018)

29. IRENA, Renewable Power Generation Costs in 2018 (2018) 